Bond University

Research Repository

\title{
Patients' Experiences and Perspectives of Telehealth Coaching with a Dietitian to Improve Diet Quality in Chronic Kidney Disease: A Qualitative Interview Study
}

Warner, Molly M.; Tong, Allison; Campbell, Katrina L.; Kelly, Jaimon T.

Published in:

Journal of the Academy of Nutrition and Dietetics

DOI:

10.1016/j.jand.2019.01.023

Licence:

CC BY-NC-ND

Link to output in Bond University research repository.

Recommended citation(APA):

Warner, M. M., Tong, A., Campbell, K. L., \& Kelly, J. T. (2019). Patients' Experiences and Perspectives of

Telehealth Coaching with a Dietitian to Improve Diet Quality in Chronic Kidney Disease: A Qualitative Interview Study. Journal of the Academy of Nutrition and Dietetics, 119(8), 1362-1374.

https://doi.org/10.1016/j.jand.2019.01.023

\section{General rights}

Copyright and moral rights for the publications made accessible in the public portal are retained by the authors and/or other copyright owners and it is a condition of accessing publications that users recognise and abide by the legal requirements associated with these rights.

For more information, or if you believe that this document breaches copyright, please contact the Bond University research repository coordinator. 


\section{RESEARCH SNAPSHOT}

2 Research question: What are patients' experiences and perspectives of the acceptability of telehealth coaching to improve diet quality in stage 3-4 chronic kidney disease?

4 Key findings: Thematic analysis of 21 interviews of patients with stage 3-4 chronic kidney disease

5 found individualized telephone and text message coaching promoting dietary self-management was

6 acceptable because it was convenient, and patients felt supported, empowered, more aware of their

7 dietary needs, and better able to prioritize and translate nutrition knowledge into eating behavior.

8 The relationship built with the coach (Registered Dietitian equivalent in Australia) from a distance

9 increased the patients' confidence to discuss diet-disease mechanisms, challenges, fears, motivators 10 and goals.

\section{ABSTRACT}

13 Background: Dietary behavior change interventions for the self-management of chronic kidney

14 disease (CKD) have the potential to slow disease progression and reduce metabolic complications.

15 Telehealth-delivered dietary interventions may assist in the self-management of CKD, although 16 their acceptability by patients is unknown.

17 Objective: This study aims to describe the acceptability and experiences of a telehealth coaching 18 intervention which utilized telephone calls and tailored text messages to improve diet quality in 19 patients with stage 3-4 CKD.

20 Design: Semi-structured interview study of adults with CKD.

21 Participants/setting: Adults with stage 3-4 CKD (n=21) aged 28 to 78 (mean 62) years, who 22 completed a 12-week telehealth-delivered dietary intervention in Queensland, Australia, were 23 interviewed from March to July 2017.

24 Data analysis: Interviews were transcribed verbatim and analyzed thematically.

25 Results: Five themes were identified: valuing relationships (receiving tangible and perceptible support, building trust and rapport remotely, motivated by accountability, readily responding to a 
27 personalized approach, reassured by health professional expertise); appreciating convenience

28 (integrating easily into lifestyle, talking comfortably in a familiar environment, minimizing travel

29 and wait time burden); empowered with actionable knowledge (comprehending diet-disease mechanisms, practical problem solving for sustainable dietary behavior); increasing dietconsciousness (learning from recurrent feedback, prompted by reiteration of messages); making sense of complexity (contextualizing and prioritizing comorbidities, gaining confidence to make dietary decisions, setting and achieving realistic goals).

34 Conclusions: Among adults with stage 3-4 CKD, individualized telehealth coaching for improving

diet quality was convenient for patients and they felt supported and empowered to navigate recommendations and prioritize dietary behavior changes. Telehealth-delivered dietary interventions appear to be well accepted by patients as a way of providing regular, tailored contact with a health professional to support dietary management in CKD.

\section{BACKGROUND}

Chronic kidney disease (CKD) affects over $10 \%$ of the population worldwide. ${ }^{1}$ Management of end stage kidney disease requires dialysis or kidney transplant; which is resource-intensive for healthcare systems, associated with high mortality, and severely impairs quality of life of the patient and their family. ${ }^{2}$ Preventing CKD progression through dietary self-management strategies has been identified as high priority research among patients ${ }^{3-5}$ and health professionals. ${ }^{6,7}$

\section{Optimizing nutrition and dietary patterns through frequent, individualized care improves} management of CKD. ${ }^{5,8}$ However, providing adequate nutrition care includes geographical barriers such as establishing professional expertise at the point of care for patients, and obtaining adequate time to individualize complex nutritional needs with consideration of comorbid conditions, quality of life, and social and personal circumstances. ${ }^{4,7,9,10}$ 
53 Telehealth interventions improve healthcare accessibility for both health professionals and patients.

54 Telehealth delivery modes include telephone, mobile applications, text or photo messaging, internet, email, and/or video. Such interventions can be effective in reducing risk factors for chronic disease through improving adherence to dietary recommendations. ${ }^{11-14}$ A further benefit of telehealth includes being able to facilitate an increased frequency of contact between the patient and healthcare professional, ${ }^{11,14}$ which is desired by people with CKD to allow regular feedback and support incremental and sustainable dietary changes. ${ }^{5}$

Evaluating acceptability is important in the pilot testing of complex interventions to ensure they are appropriate for expansion. ${ }^{15}$ 'Acceptability' reflects the extent to which people receiving an intervention consider it to be appropriate, based on experienced cognitive and emotional responses to the intervention. ${ }^{16}$ A more detailed understanding of the acceptability of novel approaches is needed to inform future telehealth behavior change interventions in CKD. This study aims to describe the patients' acceptability and experiences of a telehealth coaching intervention using telephone calls and tailored text messages to improve diet quality in patients with stage 3-4 CKD.

\section{METHODS}

\section{Context}

This semi-structured interview study included participants from the intervention group at the completion of the first 12 weeks of the Evaluation of iNdividualized Telehealth Intensive Coaching to promote healthy Eating and lifestyle in stage 3-4 CKD (ENTICE-CKD) trial. ${ }^{17}$ The randomized controlled trial took place from November 2016 to November 2017. The intervention involved a workbook, face-to-face visits at baseline and endpoint, and telehealth coaching by an Accredited Practising Dietitian (Registered Dietitian equivalent). 
79 The intervention group $(\mathrm{n}=41)$ received 6 telephone calls ( 1 every 2 weeks) and tailored text

80 messages (1 to 4 per week as determined by each participants preference, which was discussed

81 during the first call). Each participant received the telephone calls and text messages from the same dietitian ( 1 of 2 coaches) for the entirety of the intervention. Each of the telephone calls (mean length $24 \pm 10$ minutes) were guided by corresponding sections in the 90 -page workbook: goal setting; the Australian Dietary Guidelines (Table 1 - online only); physical activity guidelines; diet in kidney disease; self-monitoring checklists; and a reference section with recommended websites, apps, and recipes. The dietitians worked together with participants to develop realistic and achievable goals. The intervention aimed to reduce sodium intake and improve adherence to the Australian Dietary Guidelines ${ }^{18}$ (as recommended in the current Caring for Australasians with Renal Impairment (CARI) guidelines ${ }^{19}$ ), and Australian Physical Activity Guidelines, ${ }^{21}$ to prevent CKD progression. The dietitian used motivational interviewing techniques to tailor the intervention calls to participant's individual goals, co-morbidities, and current stage of change. A summary of the Australian dietary guidelines and comparison to international CKD guidelines can be found in Table 1 (online only). The text messages contained self-monitoring guidance, goal checks and educational tips. A library of text messages was designed by the dietitians and reviewed by several patients, nephrologists and members of the investigator team to ensure accurate comprehension of the evidence-based practice guidelines. The text messages (up to 140 characters) were imported into a web-based, semiautomated text message management platform, ${ }^{22}$ which was designed to tailor the text messages to participants based on: participant's name; individual goals; barriers to achieving goals; and, participant-identified solutions to overcoming those barriers. These tailoring variables were collected and modified as required by the coaches during the initial and subsequent coaching calls. 
104 The telehealth intervention was built upon the framework of Social Cognitive Theory, ${ }^{23}$ with a

105 patient-centered focus on dietary self-management. The most prevalent constructs of social

106 cognitive theory were expectation (through education), reinforcement (through coaches' feedback

107 during calls and text-message goal-check replies), and self-efficacy (through encouraging self-

108 monitoring and problem solving). The registered dietitians (Australian equivalent) undertook 1 day

109 of training in motivational interviewing by a dietitian with no involvement in the study protocol (the

110 dietitian had been trained by a member of Motivational Interviewing Network of Trainers). In

111 addition, all coaching materials (the call scripts, text messages and the workbook) were reviewed by

112 an external party to ensure all ENTICE-CKD materials complied with motivational interviewing

113 principles. Fidelity was continuously assessed in team meetings throughout the study duration as

114 explained elsewhere. ${ }^{17}$ The control group were not involved in the present study. The trial,

115 including semi-structured evaluation interviews, was registered in the Australian New Zealand

116 Clinical Trials Registry (ACTRN12616001212448) ${ }^{17}$ and approved by the Metro South Health

117 Service District Human Research Ethics Committee (EC00167) and Bond University Human

118 Research Ethics Committee (EC00357).

120 Participant selection

121 All participants who completed the ENTICE-CKD intervention $(n=41)$ were eligible for interview.

122 Patients were recruited by research assistants from three large teaching hospitals in Queensland,

123 Australia. ${ }^{17}$ Inclusion criteria consisted of (1) stage 3-4 CKD (eGFR 15-60mL/min/1.73m²); (2)

124 owned a mobile telephone; (3) greater than 18 years of age; (4) able to understand English.

125 Telehealth coaches consecutively sampled participants for semi-structured interviews via telephone

126 or text message as they completed the 12 th week of the trial. Participants were recruited until data

127 saturation occurred. Consecutive sampling was used due to study time constraints. All participants

128 provided written informed consent to complete an evaluation interview at baseline of the ENTICE-

129 CKD telehealth intervention and additional verbal consent prior to interview. 


\section{Data collection}

132 Participant characteristics were collected from medical records by the telehealth coach (Registered

133 Dietitian equivalent). ${ }^{17}$ The interview guide (Figure 1) was developed based on: constructs of

134 acceptability (attitude, burden, perceived effectiveness, ethicality, intervention coherence, and self-efficacy)

$135{ }^{16}$; previous literature relating to telehealth, behavior change, and chronic kidney disease; discussion among

136 the research team; and 2 pilot interviews within the research team. ${ }^{424-27}$ Modifications to the interview

137 guide included the addition of story-telling questions and prompting to determine why the

138 participant felt a particular way. Modifications can be seen in Figure 1. The guide covered usability

139 of telephone calls and text messaging, barriers and facilitators of actioning telehealth intervention

140 recommendations, and experiences of behavior change techniques involved in the telehealth

141 intervention (e.g. goal setting). The first author (not involved in trial facilitation and previously

142 unknown to participants) conducted the semi-structured interviews from March to July 2017 in a

143 location separate to the recruiting hospitals, by telephone or face-to-face as preferred by the

144 participant. The interviews were recorded and transcribed verbatim by the first author. Interviews

145 were conducted until data saturation, which was discussed among the research team. No interviews 146 were repeated.

\section{Data analyses}

149 Transcripts were coded in HyperRESEARCH ${ }^{28}$ qualitative data management software. Based on the 150 principles of grounded theory ${ }^{29}$ and thematic analysis, ${ }^{30}$ two researchers familiarized themselves

151 with the data line-by-line and inductively identified initial codes prior to discussion. The researchers established the coding structure to develop themes within the data, which was refined and finalized through discussion. This form of investigator triangulation enhances the credibility of the analytical framework and ensures confirmability, whereby the full range and depth of data were captured in the analysis. ${ }^{31}$ 


\section{RESULTS}

Participants

159 Of the 41 ENTICE-CKD intervention participants, 22 were approached, and 21 (95\% of those 160 approached) agreed to complete a semi-structured interview; one was unable to be interviewed due 161 to long-term travel commitments. The interviews ranged from 20 to 96 minutes (mean 49 min), and 162 all except one were completed by telephone (one face-to-face). Only the interviewer and the 163 interviewee were present. Participants' characteristics are presented in Table 2.

\section{Themes}

Five themes were identified: valuing relationships, appreciating convenience, empowered with actionable knowledge, increasing diet-consciousness, and making sense of complexity. The subthemes are described below and additional quotations to support each theme are provided in Table 3. Figure 2 shows a thematic schema to summarize and illustrate the links among themes.

\section{Valuing relationships}

172 Receiving tangible and perceptible support: Prior to the telehealth intervention, participants 173 perceived that clinicians were generally "too busy to worry" and not "really interested". They 174 believed that the telephone calls and text messages during the telehealth intervention provided support and encouragement. They felt cared for by the coaches and were thus better prepared to accept their advice. For some participants, receiving the text messages meant 'you haven't been forgotten ... it's like someone's out there thinking of you"' (Female, 60's).

Building trust and rapport remotely: Participants developed a trusting relationship with their coach over the telephone - “we're speaking ... it's not like you're left hanging” (Female, 60's).

181 Participants found the telehealth coach "easy to talk to", "engaging", "positive", "approachable" 182 and like "one of the family". They felt comfortable discussing their fears, such as medications and 
183 dialysis. The telephone coaching sessions allowed time for questions, which helped the participants

184 to feel heard and important without being rushed.

185

186 Motivated by accountability: Participants strived to adhere to dietary recommendations to improve 187 wellbeing, self-satisfaction, or to impress their doctor, dietitian, family, or friends. Some were 188 motivated to participate in the telehealth intervention because it was "for research" and thus 189 expected they were contributing to healthcare quality improvement. Having frequent contact and a 190 good relationship with the telehealth coach helped participants to feel more accountable - "I knew 191 I'd be getting another [text message] this week ... we were like going walking on the road together" 192 (Female, 60's). Some felt they had to monitor their progress by keeping a food diary - "without the support or encouragement from someone else then self-monitoring [with a diary] can be just a word, or two words [on paper], but with the encouragement from that outsider, then those two words become important" (Male, 60's). Some participants discussed the telehealth intervention with family and friends so they could be held accountable to reach their goals.

Readily responding to a personalized approach: Participants were more interested in and felt more motivated to respond to messages about their individual goal and those that included their name or the name of their telehealth coach - "I was getting some [text messages] from [my coach] and I was getting some [text messages] that were computer generated ... you could just tell that they were a bit more - perfect" (Female, 30's). Some participants felt each type of text message (educational tip, personalized goal check, self-monitoring prompt) was necessary - "they're equally as important as the other, but for me I prefer getting a pat on the back than a suggestion of what I can eat" (Male, 60’s). Participants who chose less frequent text messages (e.g. 2 per week) did so because they did not find the text messages to provide additional benefit to what they received from the telephone calls and workbook. 
Reassured by health professional expertise: Some participants felt that friends and family “don't

210 understand" their situation, whereas their telehealth coach knew "about kidney health" and dietary

211 management. Having ready access to a registered dietitian (Australian equivalent)) was reassuring,

212 and this fostered self-efficacy in some participants who then gained confidence to ask their doctor

213 questions about their health condition(s). Participants trusted the information in the text messages

214 and workbook and relied on these to guide their food choices between calls with their telehealth

215 coach.

\section{Appreciating convenience}

218 Integrating easily into lifestyle: Participants noted that the flexibility in the schedule of the calls and

219 the length of the calls did not disrupt their lifestyle. For example, they were still able to work, 220 travel, and take care of family - "it was quite easy, that's what I enjoyed about it, was having that 221 flexibility" (Male, 40's). Participants appreciated the ability to read the text messages in their own time - "you look at your phone any time ... the message is always there" (Female, 60's).

Talking comfortably in a familiar environment: Participants were comfortable talking in their home, at work, or in the car as there were "no interruptions" and some felt less "nervous" than they feel when seeing a health professional in a clinic. In contrast, participants had previously felt rushed in clinic and were conscious to avoid taking the clinician's time from "worse off people" seen in the waiting room. They also found it difficult to retain information that was relayed in the clinical setting - "you go there [into clinic], and you walk away, and you forget half of it" (Male, 60's).

231 Minimizing travel and wait time burden: Participants appreciated that they could access the 232 telehealth intervention without travelling from remote areas, navigating public transport, finding 233 and paying for parking, walking " $a$ mile with an aching leg" from the car park, and dealing with the 234 frustratingly long wait times at the clinic - "With the phone it's direct, it's immediate; in the clinic 
235 you go in, you go waiting ... I've found the biggest problem is sitting around waiting to see

236 somebody" (Male, 60's). The calls were "less hassle" than face-to-face and minimized the burden

237 of clinic visits.

239 Empowered with actionable knowledge

240 Comprehending diet-disease mechanisms: Participants were able to comprehend nutrition and

241 disease mechanisms more and more after each telephone call, which raised self-efficacy and helped

242 to justify food choices - "[my coach] took it a step further and not only explained what the big

243 [nutrition] problems were but how they affect the kidneys" (Male 60's). The workbook provided a

244 "simple explanation of the technical stuff" and the new knowledge motivated participants to

245 improve their self-management.

"Now I'm aware of what was causing most of the problem, of course was most of the fluid intake, I'm trying very hard to still keep my fifteen hundred mls [milliliters] of fluid a day, and that seems to have worked" (Male 60's)

Practical problem solving for sustainable dietary behavior: Participants found it easier to unravel and resolve their dietary concerns by "just having a bit of information at a time, so it's not overwhelming" (Female, 60's). The telehealth coaches had "good ideas" and could suggest "little things" to change. Some preferred to have a "clear cut" list of "good foods" and "foods to avoid" without the "long rigmaroles of why". After the coaching call on label-reading, they felt better able to understand food labels to make food choices - "I never ever looked at labels before, but, when you understand them, there's a big difference" (Male, 60's). Participants felt better equipped to improve their nutrition intake by forming habits of: reading food labels; choosing lower sodium options; and having "the right foods in the house" (Female, 30's). 
261 Learning from recurrent feedback: Two weeks between calls was believed to be an optimal time

262 frame for keeping dietary self-management at the forefront of the mind, as well as for reviewing 263 behavior change and receiving feedback - "It's good to have someone to chat to every few weeks ...

264 you can go over any questions" (Female, 30's). Feedback also came from the text messages and 265 workbook, which were "handy" to "check on things" learned in the telephone coaching sessions, 266 such as food groups and portion sizes.

268 Prompted by reiteration of messages: Frequent text messages relating to the participants goals were 269 "good reminders" and useful for "staying on track" to change habits. Reiteration of messages 270 helped participants to take mindful action - "I sort of knew [the portion sizes], but they reinforce it 271 all the time, which is a really good thing" (Male, 60's). Participants used visual cues to remind 272 them of their diet goals by keeping the workbook "in its spot" in a visible place and using it as a 273 "reference" tool. Becoming aware of intake of fluid, high sodium foods, food groups and portion 274 sizes was considered as necessary for sustaining appropriate dietary habits.

"I'm aware of like the salt intake and reading labels and that type of thing, which I've never been aware of before, you just go shopping and you put it in your trolley" (Female, 60’s)

Making sense of complexity

280 Contextualizing and prioritizing comorbidities: Participants felt overwhelmed by comorbid conditions creating physical and emotional challenges for changing behavior. Participants reported that telehealth coaches "broke down" multiple "issues" into "simple basic understandings" and 283 helped participants to prioritize health behaviors. all these things ... get like the broader, you know the whole picture ... I found that 
helpful ... I'm certain it's brought it all together for me" (Male, 70's)

Gaining confidence to make dietary decisions: Participants found it easier to remember

dichotomized and measurable dietary recommendations such as: food swaps and checklist; food

groups with number of servings per day; recommended portion sizes; and food label cut off points for particular nutrients. This quantifiable information empowered participants to make dietary decisions with confidence and to identify "which [food] is good or which is bad" (Male, 70's).

Setting and achieving realistic goals: Setting specific goals was well accepted for some participants who felt driven to "hit a target" (Male, 40's). As the participants could feel changes in their body as their goals progressed, they became more engaged with their telehealth coach and the telehealth intervention - "that's what encouraged me to go on [with the telehealth intervention], because I could see the change, as I was making little adjustments and they were only little adjustments, they weren't big adjustments ... all these little adjustments amount to great leaps and bounds" (Male, 60's). Some participants wrote about their goals in the workbook and referred back to them for motivation to continue their efforts. However, some did not like to write about their goals and behaviors because they considered it burdensome, felt it was unnecessary because they were already aware of their behaviors, or they refused to be reminded of their kidney disease - "I didn't

\section{DISCUSSION}

308 The results show that participating adults with stage 3-4 CKD accepted the use of telehealth coaching to improve dietary self-management as it met their needs for social, emotional and

310 practical reasons. Participants valued the relationship built with their telehealth coach because they

311 felt supported, empowered, and confident in discussing diet-disease mechanisms, goals, motivators, 
312 challenges and fears with their coach, which helped them to feel their diet-related comorbidities

313 (e.g. diabetes, gout) and lifestyle needs (e.g. time and social commitments) were thoroughly

314 considered. This finding aligns with the principles of motivational interviewing, whereby

315 establishing a mutually trusting and respectful helping relationship, otherwise known as

316 'engagement', is necessary for a consultation to flow and motivate behavior change. ${ }^{34}$ Motivational

317 interviewing emphasizes the importance of non-verbal communication skills in the engagement

318 process. $^{34}$ Previous literature shows that the physician-patient working alliance is positively

319 associated with improved patient adherence and outcomes. ${ }^{35}$ Interestingly, engagement was

320 successful without body language communication in this telephone and text message intervention.

321 Participants found the frequency of contact with their dietitian coach beneficial in engaging and

322 strengthening their relationship.

324 All participants appreciated access to health professional support without the need for travel,

325 regardless of the distance between their home and their nearest health center. It was convenient for 326 participants to integrate telephone calls and text messages into their daily lives, particularly when 327 coaches were flexible with telephone call times. Additionally, participants felt comfortable 328 discussing their dietary needs when they were in a familiar setting (as compared to a clinic setting), 329 and perhaps more likely to retain new information. Previous studies have shown that patients with 330 CKD often feel rushed in clinic, ${ }^{4}$ and desire flexibility in their treatment schedule. ${ }^{5}$ In contrast, this 331 telehealth-delivered dietary intervention allowed participants to feel there were opportunities to 332 approach their coach with questions at any time. These findings are relevant because poor 333 adherence to dietary advice for chronic disease management is an ongoing problem, ${ }^{12}$ and 334 adherence may be assisted through maximizing engagement and minimizing the burden of clinic 335 appointments. 
337 Participants gained awareness of their dietary needs and felt better able to prioritize and translate

338 nutrition knowledge into food choices and eating behavior. Palmer and colleagues ${ }^{4}$ synthesized

339 patient views on dietary and fluids restrictions in CKD and found 'becoming empowered' assisted

340 problem solving. Likewise, this present study revealed that participants felt empowered with the

341 knowledge they gained and were able to solve problems and form sustainable habits for improved

342 dietary behavior. This study consolidates these findings and now suggests that empowerment can be

343 achieved from a distance, using telephone and text message communication.

345 Perspectives and attitudes towards the telehealth intervention were not found to be unique to 346 specific demographic characteristics. It was noted that participants who chose infrequent text 347 messages were in the 60-79-year age group, however, there were more participants in the same age 348 group choosing frequent text messages. Multiple intervention materials to guide behavior change 349 was viewed essential by participants, as each were used differently to support learning and to 350 motivate healthier food-related decisions. This finding aligns with that of previous research, which 351 showed behavior change interventions are more effective when multiple intervention delivery 352 modes (e.g. telephone calls, text messages, print materials) are implemented. ${ }^{14}$

354 A preluding focus group study ${ }^{5}$ found that adults with stage 3-4 CKD wanted a telehealth-delivered 355 dietary-focused program involving motivating clinicians, regular feedback, reassurance, and 356 flexibility, which they thought may be assisted with text messages. ${ }^{5}$ This present study found the 357 individualized text messages were viewed to: enhance participant-clinician interactions; strengthen 358 support and accountability; and prompt participant behavior change towards their own goals.

359 Participants experiences of telehealth strengthen the current evidence which indicates the need for: 360 multiple delivery modes within a behavior change intervention, ${ }^{14}$ individualizing telehealth delivery 361 modes to the patient, ${ }^{36}$ and where applicable, personalizing and tailoring the frequency of text 362 messages $^{37}$ in chronic disease self-management. 
364 Addressing social support is fundamental to successful behavior changes interventions. Participants 365 in this study valued support and accountability for changing dietary behavior. Specific behavior 366 change techniques within a 'social support' domain have been identified previously, including 367 general-, emotional- and practical-social support. ${ }^{24}$ Future telehealth interventions addressing 368 dietary behavior change may benefit from formally incorporating these social support components 369 into the intervention content to further empower patients to change behaviors for long-term disease management.

This study addresses the lack of evidence in the acceptability of telehealth in improving the dietary self-management of patients with stage 3-4 CKD. The credibility of the study was strengthened by sampling participants with a diverse range of demographic characteristics, use of an appropriate semi-structured interview guide, investigator triangulation, in-depth description of the study context and findings, and by providing supporting quotations. ${ }^{31}$ The interview guide, verbatim transcription of recorded interviews and the use of qualitative data analysis computer software reinforces the dependability of the findings. ${ }^{31}$ However, there are some limitations to consider. The scope of this study did not include participants from the control group of the ENTICE-CKD trial and may not capture other views of participants who received the text message only intervention. Other measures of intervention efficacy, such as body weight and biochemistry, have been collected and are in preparation for publication. A more thorough assessment of the dietitians' proficiency in motivational interviewing before and during the intervention (for example, using the Motivational

384 Interviewing Treatment Integrity coding system) would have strengthened the fidelity assessment. 385 Future studies may consider investigating the acceptability of text message-only interventions in dietary self-management of stage 3-4 CKD. Finally, this study is limited to English-speaking people who own a mobile telephone and are willing to participate in a telehealth trial. Therefore, the transferability to non-English speaking patients and those who do not use a mobile phone is 
389 uncertain. Suggestions for future telehealth-delivered dietary management interventions are shown 390 in Table 4.

\section{CONCLUSIONS}

393 Individualized telehealth coaching may be acceptable to adults for supporting dietary self-

394 management in stage 3-4 CKD because it can be convenient and help people to feel supported and

395 empowered to make sense of their needs and prioritize dietary behavior changes. This study

396 suggests that adults with stage 3-4 CKD may want more support with their dietary self-management

397 through building trusting relationships with their clinician. Achieving this in practice may be

398 facilitated using individualized telephone and text message interventions. 


\section{REFERENCES}

399 1. Bello AK, Levin A, Tonelli M, et al. Assessment of global kidney health care status. JAMA. 2017;317(18):1864-1881.

401 2. Eckardt KU, Coresh J, Devuyst O, et al. Evolving importance of kidney disease: from subspecialty to global health burden. Lancet. 2013;382(9887):158-169.

3. Tong A, Sainsbury P, Carter SM, et al. Patients' priorities for health research: Focus group study of patients with chronic kidney disease. Nephrology, dialysis, transplantation : official publication of the European Dialysis and Transplant Association - European Renal

4. Palmer SC, Hanson CS, Craig JC, et al. Dietary and fluid restrictions in CKD: A thematic synthesis of patient views from qualitative studies. American journal of kidney diseases : the

5. Kelly JT, Campbell KL, Hoffmann T, Reidlinger DP. Patient experiences of dietary management in chronic kidney disease: A focus group study. J Ren Nutr. 2017;S10512276(17):30192-30199.

413 6. Hemmelgarn BR, Pannu N, Ahmed SB, et al. Determining the research priorities for patients with chronic kidney disease not on dialysis. Nephrology, dialysis, transplantation : official publication of the European Dialysis and Transplant Association - European Renal Association. 2017;32(5):847-854.

417 7. Stevenson J, Tong A, Campbell KL, Craig JC, Lee VW. Perspectives of healthcare providers on the nutritional management of patients on haemodialysis in Australia: An interview study. BMJ Open. 2018;8(3):e020023.

8. Ash S, Campbell KL, Bogard J, Millichamp A. Nutrition prescription to achieve positive outcomes in chronic kidney disease: A systematic review. Nutrients. 2014;6(1):416-451. 
422 9. Hand RK, Steiber A, Burrowes J. Renal dietitians lack time and resources to follow the NKF KDOQI guidelines for frequency and method of diet assessment: Results of a survey. $J$ Ren Nutr. 2013;23(6):445-449.

10. Australian Institute of Health and Welfare. Chronic kidney disease: Regional variation in Australia. Cat. no. PHE 172. 2013; https://www.aihw.gov.au/getmedia/832efa35-2b80-4fdf9308-3a87db47c64b/15100.pdf.aspx?inline=true. Accessed 25 January, 2019.

11. Kelly JT, Reidlinger DP, Hoffmann TC, Campbell KL. Telehealth methods to deliver dietary interventions in adults with chronic disease: a systematic review and meta-analysis. Am J Clin

12. Desroches S, Lapointe A, Ratte S, Gravel K, Legare F, Turcotte S. Interventions to enhance adherence to dietary advice for preventing and managing chronic diseases in adults. The Cochrane database of systematic reviews. 2013(2):CD008722.

434 13. Goode AD, Reeves MM, Eakin EG. Telephone-delivered interventions for physical activity

14. Beall RF, Baskerville N, Golfam M, Saeed S, Little J. Modes of delivery in preventive intervention studies: A rapid review. Eur J Clin Invest. 2014;44(7):688-696. and dietary behavior change: An updated systematic review. American journal of preventive medicine. 2012;42(1):81-88.

17. Australian New Zealand Clinical Trials Registry. The Evaluation of iNdividualized Telehealth Intensive Coaching to promote healthy Eating and lifestyle in Chronic Kidney Disease. 2016; Trial ID ACTRN12616001212448. Available at: 

January, 2019.

450 18. National Health and Medical Research Council. Australian dietary guidelines. 2013; https://www.eatforhealth.gov.au/guidelines. Accessed 25 January, 2019.

19. Kidney Health

Australia.

Chronic Kidney

Disease

Guidelines. http://www.cari.org.au/CKD/ckd_guidelines.html. Accessed 25 January, 2019.

20. National Kidney Foundation. KDOQI Clinical Practice Guidelines and Clinical Practice Recommendations for Diabetes and Chronic Kidney Disease. American journal of kidney diseases : the official journal of the National Kidney Foundation. 2007;49(2 Suppl 2):S12-

21. Department of Health. Australia's physical activity and sedentary behaviour guidelines for adults. 2014; http://www.health.gov.au/internet/main/publishing.nsf/Content/health-pubhlthstrateg-phys-act-guidelines. Accessed 25 January, 2019.

22. The University of Queensland. Propelo. 2018; www.propelo.com.au. Accessed 25 January, 2019.

23. Bandura A. Social foundations of thought and action: A social cognitive theory. Prentice-Hall Inc; 1986.

24. Michie S, Wood CE, Johnston M, Abraham C, Francis JJ, Hardeman W. Behaviour change techniques: The development and evaluation of a taxonomic method for reporting and describing behaviour change interventions (a suite of five studies involving consensus methods, randomised controlled trials and analysis of qualitative data). Health Technol Assess. 2015;19(99):1-188.

25. Lo C, Ilic D, Teede H, et al. Primary and tertiary health professionals' views on the healthcare of patients with co-morbid diabetes and chronic kidney disease - a qualitative study. BMC Nephrol. 2016;17(1):50. 
473 26. Cummings KM, Becker MH, Kirscht JP, Levin NW. Intervention strategies to improve compliance with medical regimens by ambulatory hemodialysis patients. J Behav Med. $1981 ; 4(1): 111-127$.

27. Bosworth HB, Olsen MK, McCant F, et al. Hypertension Intervention Nurse Telemedicine Study (HINTS): Testing a multifactorial tailored behavioral/educational and a medication management intervention for blood pressure control. Am Heart J. 2007;153(6):918-924.

28. HyperRESEARCH [computer program]. Version 3.7.5. USA: Researchware Inc; 2015.

29. Glaser B, Strauss A. The Discovery of Grounded Theory: Strategies for Qualitative Research. New Jersey: Transaction Publishers; 2012.

30. Braun V, Clarke V. Using thematic analysis in psychology. Qual Res Psychol. 2006;3(2):77483 101.

31. Lincoln Y, Guba E. Naturalistic inquiry. London, UK: Sage Publications; 1985.

32. Census of Population and Housing: Socio-Economic Indexes for Areas (SEIFA). Australian

33. Australian Government

$$
\text { of }
$$

Statistics;

2011. https://www.homeaffairs.gov.au/visas/supporting/Pages/skilled/regional-post-codes.aspx.

34. Miller W, Rollnick S. Motivational Interviewing: Helping People Change. 3rd ed. New York, USA: The Guilford Press; 2013.

35. Fuertes JN, Toporovsky A, Reyes M, Osborne JB. The physician-patient working alliance: Theory, research, and future possibilities. Patient Educ Couns. 2017;100(4):610-615.

36. Dinesen B, Nonnecke B, Lindeman D, et al. Personalized Telehealth in the Future: A Global Research Agenda. J Med Internet Res. 2016;18(3):e53. 
498 37. Partridge SR, Allman-Farinelli M, McGeechan K, et al. Process evaluation of TXT2BFiT: A multi-component mHealth randomised controlled trial to prevent weight gain in young adults. Int J Behav Nutr Phys Act. 2016;13:7. 
Figure 1. Semi-structured Interview Schedule for the Evaluation of

iNdividualized Telehealth Intensive Coaching to promote healthy Eating and lifestyle in stage 3-4 CKD (ENTICE-CKD) trial, Queensland, Australia (November 2016 - November 2017).

\section{Warm up, rapport building, experiences}

I'm interested to hear about your story with a kidney condition. Would you be able to tell me about your story from when you first found out, how you felt and your journey up until now?

- Can you tell me how you felt, or your initial reactions, when you were first diagnosed?

- What was your experience with the healthcare system and dietitians before the ENTICE program?

Can you talk me through how you got involved in the program? What happened?a

- How and why did you sign up? (Motivation? Knowledge? Priorities?)

- Who influenced your decision to take part in the program? How? Why?

- Did your doctor recommend the program? Did they have an influence on your decision to take part? (Support/pressure? Influence of medical professionals?) What happened after you signed up for the program? Did you meet with a dietitian? How did you find that?

\section{Barriers and facilitators of adherence to program}

Before ENTICE, did you have any needs, challenges, concerns about diet?

- Could you briefly tell me about that? ${ }^{\mathrm{a}}$

- To what degree does the ENTICE program meet your needs or address what you want? How? Why?

- What do you like most/least about being involved in the program - why?

- What were some of the things that made the program easy/difficult to take part in? 
- What are your thoughts on being in familiar surroundings while you were talking to your coach?

\section{Telehealth delivery methods}

Let's move on to your experiences with the phone calls.

- What did you expect from the calls and did they meet your expectations?

- What are your thoughts on never having seen your coach and building a relationship with them?

- How do you think using the telephone is different to seeing someone in person? Feel any different being in a familiar environment compared to a clinic?

- Can you share some things that made the phone calls easier/harder than seeing your coach in person?

- Were you able to make the calls at a suitable time - how?

- What do you think about the frequency of the calls? - why?

- Did you feel you were rushed during the calls? How did you feel about the length of the calls?

- Do you have anything more to add about the phone calls? ${ }^{\mathrm{a}}$

Let's talk about the text messages now, ${ }^{\mathrm{a}}$ what did you think about getting the text messages from your coach?

- Can you give me an example of a text message that you liked the most/least?

- Do you think the text messages were necessary - why? ${ }^{\mathrm{a}}$

- What do you think about how frequently you got the text messages? Why? ${ }^{\mathrm{a}}$

- Do you have anything more to add about the text messages?

You got a workbook at the start of the program.

- What are your thoughts on the information in the workbook? - why? ${ }^{\mathrm{a}}$ 
- Can you give me an example of something from the workbook that had an impact on you? (Why? Motivation? Knowledge?)

- Did you have any difficulties understanding the information in the workbook?

- Did you show the workbook to anyone? Who? Why? What did they think?

Do you have anything more to add about the workbook?

\section{Usability of the program}

Can you think of an example recommendation that your coach gave you about your diet or your lifestyle?

What are some things that helped you/made it hard for you to follow recommendations?

Why? ${ }^{\mathrm{a}}$

\section{Goal setting and self-monitoring}

What are your thoughts on setting health goals?

- How do you feel about goal setting?

- Can you tell me about your experience with goal setting before the program?

- Did you set goals in the program? When? Are you able to tell me about one of your goals?

- Do you think ENTICE helped you to achieve your goals - why?

One of the aims of ENTICE is to improve self-monitoring, do you know what selfmonitoring means? (Stuff you'll do without people reminding you, like writing down or taking note of what you eat or how active you've been) ${ }^{\mathrm{a}}$

- Do you find you do that? Why?

- What impact do you think the program has had on your self-monitoring?

- The way you go about it? How often?

How confident do you feel with monitoring your diet? Why?

\section{Behavior change}


You have made some changes to your lifestyle in order to meet your goals [example]

- Will these changes be something that you'll continue to do? How? Why?

- Can you tell me about your motivation to make changes before the program?

How and why did your motivation change during the program?

- How do you feel about keeping motivated after the program?

Do you feel like your daily activities have changed since before the program? How?

Eating behavior? Purchasing of foods? How physically active you are?

\section{Experiences}

Did you feel that the recommendations from your coach were specific to you and nobody else?

- Can you give an example of when you felt this way? ${ }^{\mathrm{a}}$

- Were the recommendations clear? How? Why? ${ }^{\mathrm{a}}$

- Do you understand why the advice was given to you?

- Do you think the program and the telephone sessions were suited to your culture?

Did you share your experiences with the program with anybody else?

- Family, friends, other health professionals? How? Why? Did you find it helpful?

Imagine you became director of the hospital and you had the power to improve the services for people with kidney disease. What would be the top 2 changes you would make to improve the care and support for people with kidney disease? ${ }^{\mathrm{a}}$

\section{Closing}

We would like you to help us evaluate the program to help improve it and the difference it makes to patients. Is there anything that you think would be important to mention that we haven't covered?

Thank you.

${ }^{\mathrm{a}}$ Questions/prompts added based on pilot interviews 
Figure 2. Thematic schema depicting experiences of participants after 12 weeks of the Evaluation of iNdividualized Telehealth Intensive Coaching to promote healthy Eating and lifestyle in stage 3-4 CKD (ENTICE-CKD) trial, Queensland, Australia (November 2016 - November 2017).

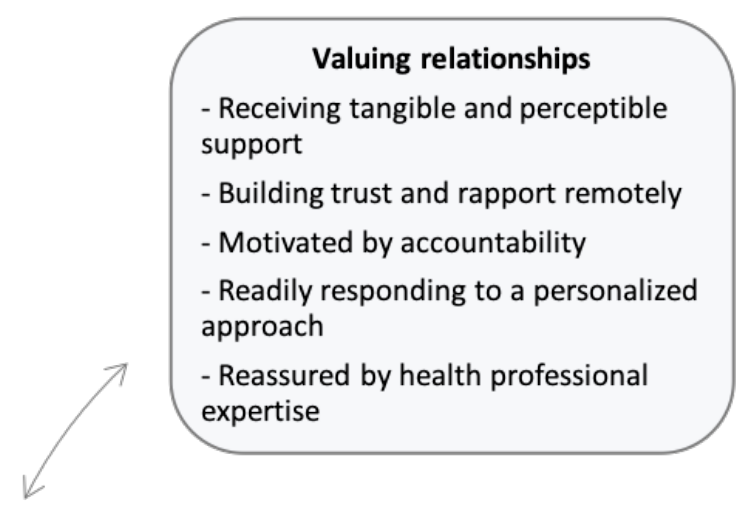

\section{Appreciating convenience}

- Integrating easily into lifestyle - Freely talking in a familiar environment

- Minimizing travel and wait time burden

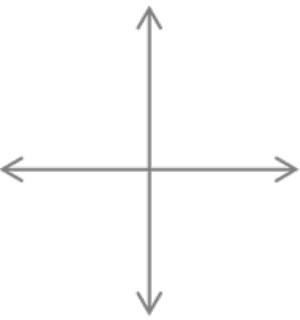

Empowered with actionable knowledge

- Comprehending diet-disease mechanisms

- Practical problem solving for sustainable dietary behavior

Making sense of complexity

- Contextualizing and prioritizing comorbidities

- Gaining confidence to make dietary decisions

- Setting and achieving realistic goals

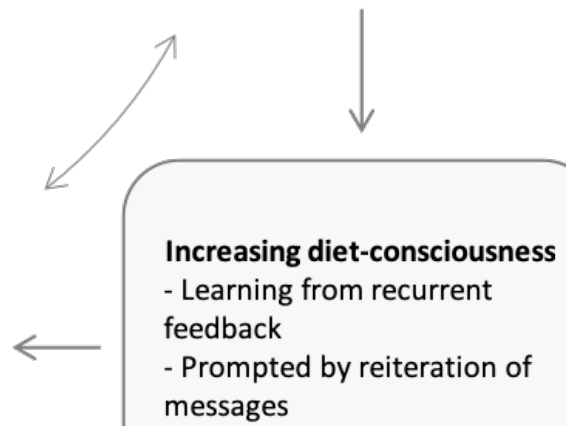


Table 1 - online only: Australian Dietary Guidelines guiding the 12-week telehealth intervention for adults participating in the Evaluation of iNdividualized Telehealth Intensive Coaching to promote healthy Eating and lifestyle in stage 3-4 CKD (ENTICE-CKD) trial, Queensland, Australia (November 2016 - November 2017).

\begin{tabular}{|c|c|c|}
\hline Dietary factors & $\begin{array}{c}\text { Australian Dietary } \\
\text { Guidelines }^{\mathrm{a}}\end{array}$ & $\begin{array}{c}\text { Comparison to CKD diet guidelines } \\
\text { (stage 3-4) }\end{array}$ \\
\hline \multicolumn{3}{|l|}{ Food groups } \\
\hline $\begin{array}{l}\text { Vegetables (servings per } \\
\text { day) }\end{array}$ & 5 & $\mathrm{NR}^{\mathrm{d}}$ \\
\hline Fruit (servings per day) & 2 & NR \\
\hline Grains (servings per day) & $3-6$ & NR \\
\hline Dairy (servings per day) & 2 & NR \\
\hline $\begin{array}{l}\text { Meat/alternatives (servings } \\
\text { per day) }\end{array}$ & 2 & NR \\
\hline \multicolumn{3}{|l|}{ Nutrients } \\
\hline Protein $\left(\% \mathrm{EEI}^{\mathrm{e}}\right)$ & $10-35$ & 10 \\
\hline Fat $(\% \mathrm{EEI})$ & $20-35$ & $<30$ \\
\hline Saturated Fat (\%EEI) & $<10$ & $<10$ \\
\hline Carbohydrates $(\% \mathrm{EEI})$ & $45-65$ & 60 \\
\hline Fibre $(\mathrm{g} / \text { day })^{\mathrm{f}}$ & $20-30$ & NR \\
\hline Sodium (mg/day) ${ }^{\mathrm{g}}$ & $<2300$ & $<2300$ \\
\hline Potassium (mg/day) & 4700 & 2400 \\
\hline Phosphorous (mg/day) & 700 & $800-1000$ \\
\hline
\end{tabular}

${ }^{a}$ As advised by the Australian Dietary Guidelines ${ }^{18}$ (which are referred to in the Caring for Australasians with Renal Impairment (CARI) guidelines ${ }^{19}$ )

${ }^{\mathrm{b}}$ Comparison based on recommendations in the KDOQI guidelines ${ }^{20}$

${ }^{\mathrm{c}}$ CKD: Chronic kidney disease

${ }^{\mathrm{d}} \mathrm{NR}$ : No recommendation

e EEI: Estimated energy intake

${ }^{\mathrm{f}} \mathrm{g}$; grams

${ }^{\mathrm{g}} \mathrm{mg}$ : milligrams 
Table 2. Characteristics of patients $(n=21)$ participating in the Evaluation of

iNdividualized Telehealth Intensive Coaching to promote healthy Eating and lifestyle in stage 3-4 CKD (ENTICE-CKD) trial, Queensland, Australia (November 2016 - November 2017).

\begin{tabular}{|c|c|}
\hline Characteristic & $\begin{array}{c}\text { Participants } \\
\text { n }(\%)\end{array}$ \\
\hline Male & $14(67)$ \\
\hline Age, mean years (min-max) & $62(22-78)$ \\
\hline$<30$ & $1(5)$ \\
\hline $30-59$ & $6(29)$ \\
\hline $60-79$ & $14(67)$ \\
\hline \multicolumn{2}{|l|}{ Marital status } \\
\hline Married/de facto & $13(62)$ \\
\hline Single/separated/divorced & $6(29)$ \\
\hline Widowed & $2(9)$ \\
\hline \multicolumn{2}{|l|}{ Ethnicity } \\
\hline Caucasian & $17(81)$ \\
\hline Indigenous & $1(5)$ \\
\hline European & $2(9)$ \\
\hline Other & $1(5)$ \\
\hline \multicolumn{2}{|l|}{ Socioeconomic status $^{\mathrm{a}}$} \\
\hline Low & $8(38)$ \\
\hline High & $13(62)$ \\
\hline \multicolumn{2}{|l|}{ Highest level of education } \\
\hline $10^{\text {th }}$ grade or below & $6(29)$ \\
\hline $12^{\text {th }}$ grade & $3(14)$ \\
\hline Tertiary & $12(57)$ \\
\hline Residing in metropolitan area $^{\mathrm{b}}$ & $9(43)$ \\
\hline \multicolumn{2}{|l|}{ Comorbidities } \\
\hline Cardiovascular disease & $16(76)$ \\
\hline Diabetes & $6(29)$ \\
\hline Gastrointestinal conditions $^{\mathrm{c}}$ & $5(24)$ \\
\hline Bone and joint conditions $^{\mathrm{d}}$ & $8(38)$ \\
\hline Liver disease & $1(5)$ \\
\hline
\end{tabular}

\footnotetext{
${ }^{\text {a }}$ Socioeconomic status calculated from the Index of Relative Socio-economic Advantage and Disadvantage (IRSAD) score $^{32}$

${ }^{\text {b }}$ Determined by postcode ${ }^{33}$

c Including gastroesophageal reflux disease, diverticulosis

${ }^{\mathrm{d}}$ Including gout, osteopenia, osteoarthritis
} 
Table 3. Selected quotations from 21 semi-structured interviews of adults after 12 weeks of participation in the Evaluation of iNdividualized Telehealth Intensive Coaching to promote healthy Eating and lifestyle in stage 3-4 CKD (ENTICE-CKD) trial, Queensland, Australia (November 2016 - November 2017).

\begin{tabular}{|c|c|}
\hline $\begin{array}{l}\text { Themes } \\
\text { and subtheme }\end{array}$ & Selected Quotations \\
\hline \multicolumn{2}{|c|}{ Valuing relationships } \\
\hline Receiving & You know someone's there, it's not like I'm going to phone you in two \\
\hline tangible and & weeks' time, two weeks you're on your own, it's like someone's out \\
\hline perceptible & there saying ... don't add salt on the table (Female, 60's) \\
\hline \multirow[t]{6}{*}{ support } & [My coach] supported me over the weeks, the phone calls every now and \\
\hline & again, every couple of weeks or so, which I think's brilliant ... just to \\
\hline & have someone there to pat you on the back every now and again and \\
\hline & explain different things and things you don't think of ... I looked \\
\hline & forward to the phone calls to tell you the truth! Because there's nothing \\
\hline & better than talking to people (Male, 60's) \\
\hline
\end{tabular}

Building trust I was able to tell [my coach] my, you know, my personal life stories and rapport (Female, 60's)

remotely I suppose [the phone is] the same thing [as going to clinic], if you get to know them, the more you talk to a person and get to know them a bit better ... you start to recognize their voice (Male, 40's)

You get much more out of a conversation than what you ever will out of a text (Male, 70's)

Motivated by I made myself committed to that phone call, but everything else is how accountability the person relates to you over the phone, how she talks or how you feel (Female, 60’s) 
The ENTICE program is really motivating me, and when I go back to see [my nephrologist] on the 30th I want her to tell me that my kidney function has improved because of the program (Male, 60's) It was just getting someone there to keep reminding me to stick to what I said I'd do (Male, 60's)

Readily The reality is every person is going to be different, and ah, I think the responding to a fact is that you talk one on one, like with [my coach] he can actually ah personalized judge what your condition is and um change the program to um to approach actually what's happening to you rather than a generalization. I think it's important that ah, that it is personalized, 'cause you get that sense that well somebody's caring sort of thing, rather than just kind of generalization (Male, 70's)

It is good that they make you feel like you're the only patient, kind of, that ah, you know, they're talking to you as an individual person, and I'm glad about that (Female, 60's)

Reassured by [When it's] someone medical telling you, you seem to listen, so yes there health are a lot of things that I have learned (Female, 60's) professional Having ah somebody that's got knowledge and experience and expertise somebody saying this is what you can do, of course that's, that's very beneficial and it's having it regular (Male, 40's) [My coach] knew what she was talking about basically, and she's easy to talk to, so, and explain things well to you (Male, 60s) 
Integrating It was convenient for me, I could just do it from home, I didn't have to

easily into go and go anywhere I could just receive calls and, and reminders you

lifestyle know as they come along (Male, 60's)

It's good you don't have to go to the dietitian either, see he rings you, wherever I am and whatever I'm doing, we've made time for it, cause otherwise you've got to get in the car and go to the dietitians office and the hospital, well see my hospitals over half an hour from here sort of thing so it's a bit of a pain to go up there, it'd be a pain to go up every week too (Male, 50’s)

It's been pretty easy because I haven't had to go out of my way to do anything really, because like I said I can be quite busy with work and things like that so I haven't had to sort of worry about doing anything extra on top of everything else, (Female, 30's)

Freely talking With the phone, it's immediate, completely straight away, you're talking in a familiar to somebody, you've got a suggestion, you've got you know what you environment need to do all mapped out, say thank you very much and hang up and move on, in all of five minutes you know and you haven't left the comfort of your own home (Male, 60’s)

Sometimes it's easier when it's not face to face ... when I go and have my [diabetes check] done every 3 months and then I've got to go and see [my doctor], and I don't know the results, I'm a bit, I'm a bit nervous face to face with him ... but if I just had to talk to him on the phone it would be easy (Female, 60's) 
[At home] was the best way to do it ... you've got the book in front of you if she wants to refer to something it um, it's quieter and peaceful so the speak (Male, 60’s)

Minimizing Well I live a long way from the clinic yes, I'm roughly an hour and a travel and wait half away. If I had to go in every day, every week, I probably wouldn't time burden have been able to do it. The cost of fuel would have been too much (Female, 60’s)

You've got to walk a kilometer up to the hospital and meet a deadline. So, you know I might leave an hour earlier and just still make it, but you can ha, sometimes leave an hour earlier and get a park and sit there for an hour, and so all those sorts of things affect your attitude, ah and you're not really concentrating and you don't think of ah, you know you're probably thinking of how your ankles hurting and how your, you know, where's the toilet when you get out of here (Male, 70's)

It's the modern world, people just ah just can't take time out to go and have a one-on-one hour consultation here and there, and um having [my coach] you know just ah, his approach over the phone is just like hey, and ah this is, I'm pretty comfortable with this (Male, 40's)

\section{Empowered with actionable knowledge}

Comprehending It's not something you can sit down with a dietitian for a, an hour once diet-disease every three months because you just, don't get that, you just can't... get mechanisms all the information from that short period of time (Male, 40's) [my goal] was to stop drinking a lot of milk, 'cause [my coach] sort of explained it to me, like what milk does and like how it is and stuff and even like the sodium content, which like when she was teaching me to 
read labels, I went over, had a look and realized you know having a little bit is ok but 3 liters a day is really bad (Male, 20's)

Practical I do read the tags on stuff that I'm going to eat and I'm very aware of the problem salt content in just about everything I eat now. But I wasn't before. Ok to solving for me it was just sodium, and sodium doesn't mean anything to me. But sustainable when it's broken down and says well sodium is salt and this is what it dietary does, um well this is when I understand that you can't have too much behavior (Male, 60’s)

Working late and things like that I'd just sort of make sure that I've got different food there to tie me over and how I'd go about that and [my coach] thought of different things that were really good ideas (Female, $30 \mathrm{~s})$

I'm a simple person and ah I can only understand simple tasks, and one task at a time, give me too many tasks and I freeze over (Male, 60's)

\footnotetext{
Increasing diet-consciousness

Learning from I think once a fortnight's [every 2 weeks is] pretty good because it gives recurrent you time to adjust to if she has um wanting to test ideas anyway, so feedback you'd sort of tell her how we're going if you adjusted to them so it gives you a couple of weeks to ah, try them out so to speak (Male, 60's) Having [the phone calls every 2 weeks] was very beneficial ... 15 to 20 , 25 minutes depending on the topic ... it's good to have ... that person to talk to, to go back to, um query what are you doing, is it right and um, and how to improve ... having it regular, not just that 'ah well I've got to go and see the dietitian now and then I won't see them again for another 6 months ... It's like an onion peeling back, just peeling back layers and
} 
layers and layers, [the workbook is] always there, it's a great resource ...

I've been refreshing myself and going back and looking at it (Male, 40’s)

Have someone there to pat you on the back every now and again um and explain different things and things you don't think of (Male, 60's)

Prompted by He sends me all these messages ... once you get out of the habit with all reiteration of these reminders it, it's a good thing (Male, 60's)

messages In [the] texts for the fortnight [2 weeks] post suggestion, [my coach] would say 'how are you going with your no potato chips' and that sort of thing and then he would give me a little reason why it's a good thing not to have so much salt (Male, 60’s)

[The text messages are] just that little back up think to keep you on track you know it, I think because I wasn't seeing him all the time or talking to him every week, yeah I think it's a good idea, it just keeps your mind, especially in the beginning, it keeps your mind on track about what you're trying to do (Female, 60's)

\section{Making sense of complexity}

Contextualizing Very helpful, because it was all broken down into simple terms! I don't and prioritizing need great big technical words that mean exactly the same thing, if you comorbidities give me something simple to do, I can get it done, and that's what the program has done ... We're all layman out here ... the ENTICE program, and [my coach], always put his words in simple, simple terms (Male, 60’s)

It's made me understand my kidney malfunction a lot more than I did before I started. To me my kidneys were retaining fluid and it was 
leaking out into my muscles, and that was it, that was the end of it, but now I understand why it's happening (Male, 60's)

Gaining I'm quite pleased I actually, it gave me a better understanding of what to confidence to do um, and you sort of feel that you are a bit ah you know how to eat and make dietary you know what to do but you don't! ... you don't actually know the right decisions quantities and things like that, that's where this program shows it to you, and it's like, it's teaching someone how to walk again (Male, 40's) I learned how to read those labels a bit better, I knew the labels were there but I didn't really understand them and I kind of know how to read the labels now, which is handy, so it has benefited me (Male, 50's)

Setting and I set [the goals] at the beginning and then um, and then in the next catch achieving up call we'd see how I was going with them and usually, the whole way realistic goals through I sort of maintained the same goals that I set at the beginning but I'd add to them each fortnight $[2$ weeks] ... one of the first goals that I set was to have um, fruit and yogurt because my dairy was down a serve and my fruit was down quite a bit, so I'd have fruit and yogurt together and then later on I found out that I needed some more um, grains ... and then there was another one to up my fiber, so I set it to have more ah raw vegetables (Female, 30's)

Giving up that soft drink was pretty hard! ... when we first started off I was having a bit too much but I've cut down, but I cut down and I've really cut down now ... the first month I was still sneaking them in, but I've slowly cut back and found the taste for water (Male, 50's) 
Table 4. Suggestions for future telehealth-delivered dietary management interventions, derived from semi-structured interviews of adults participating in the Evaluation of iNdividualized Telehealth Intensive Coaching to promote healthy Eating and lifestyle in stage 3-4 CKD (ENTICE-CKD) trial, Queensland, Australia (November 2016 - November 2017).

\begin{tabular}{|c|c|}
\hline $\begin{array}{c}\text { Intervention } \\
\text { delivery mode }\end{array}$ & Accepted intervention component \\
\hline Mixed & $\begin{array}{l}\text { Inclusion of tangible and telehealth delivery modes (e.g. hardcopy } \\
\text { workbook }+ \text { telephone calls }+ \text { text messages) to facilitate active learning } \\
\text { of diet-disease mechanisms and prompt behavior change }\end{array}$ \\
\hline Telephone & $\begin{array}{l}\text { - Telephone coaching to prioritize and agree on individualized diet- } \\
\text { related goals and motivational interviewing to encourage self- } \\
\text { monitoring of goals } \\
\text { - Regular (e.g. twice per month) telephone contact with one telehealth } \\
\text { coach to build trust, rapport and accountability, support behavior } \\
\text { change, provide feedback, and empower patients to become confident in } \\
\text { - Flexible telephone call scheduling to allow integration of dietetic care } \\
\text { into the patient's lifestyle and facilitate intervention adherence }\end{array}$ \\
\hline Text message & $\begin{array}{l}\text { - Tailored text message frequency for each individual (e.g. 1-4 messages } \\
\text { per week) } \\
\text { - Text messages personalized with individual goals and the patients or } \\
\text { coaches name }\end{array}$ \\
\hline
\end{tabular}

